\section{'Fast-track' cataract services and diagnostic and treatment centre: impact on surgical training}

L Au, K Saha, B Fernando, S Ataullah and F Spencer

\section{Abstract}

Aims To evaluate the impact of 'Action on Cataracts' and the development of Diagnostic and Treatment Centre (DTC) on cataract surgery training in the Central Manchester and Manchester Children's University Hospital's Trust.

Methods We compared all cataract extractions undertaken from April to September 2005 with the same 6-month time period over the preceding 5 years. Surgery was performed on one of four types of lists: Manchester Royal Eye Hospital standard lists (MREH), Cataract Services list, Waiting List Initiative list (WLI), and Diagnostic and Treatment Centre list (DTC). Surgeons were identified by their specific codes and divided into grades. Results The total number of cataract operations undertaken on the standard MREH lists has declined significantly over the years $\left(P<0.001 \chi^{2}\right.$ test for trend). The number of cataract operations performed by both Specialist Registrars (SpRs) and Senior House Officers (SHOs) demonstrated a statistically significant decline over the years $(P<0.001$ for both cases, $\chi^{2}$ test for trend), with the SHOs number dropping dramatically over the last 2 years. When comparing the number of operations performed by junior $\mathrm{SpR}$ s and senior SpRs, shift in the balance can be seen towards the senior surgeons. The proportion of operations performed by junior SpRs declined from $\mathbf{5 0 \%}$ in 2000 to $\mathbf{2 8 . 2 \%}$ in 2005 . Conclusion Recent changes in cataract care provision have had a significant impact on training. Our results document for the first time that both higher and basic surgical trainees were affected. Future care of our patients could be comprised owing to lack of training.
Eye (2008) 22, 55-59; doi:10.1038/sj.eye.6702512; published online 14 July 2006

Keywords: 'Action on Cataracts'; cataract; training; DTC

\section{Introduction}

Ophthalmology training in the UK is changing with the introduction of modernizing medical careers and a new curriculum that is competence based. ${ }^{1,2}$ The concept of competence is difficult and the boundaries of knowledge and skill beyond which one becomes competent are difficult to define. For many years, one of the yardsticks by which ophthalmologists in training have been measured has been the number of cataract extractions performed. This measure is clearly not wholly reliable in assessing a trainees overall competence; however, having performed a minimum of 300 cataract operations during higher surgical training is the current college requirement for completion of training. ${ }^{3}$ It is assumed that at this point the trainee will be competent in cataract surgery. The number of cases performed by an individual throughout his or her training is influenced by many factors, for example, the trainee's own level of skill, initiative used, and opportunities available. We consider that the opportunity for trainees to perform cataract surgery may be changing nationally as a consequence of the changes in delivery of ophthalmic care, particularly in cataract surgery as we felt significant changes had occurred locally. In 1999, 'Action on Cataracts' was published by the NHS Executive. ${ }^{4}$ The aims were to streamline the pathway of diagnosis
Manchester Royal Eye Hospital, Manchester, UK

Correspondence: $\mathrm{L} A \mathrm{Au}$ Manchester Royal Eye Hospital, Oxford Road, Manchester M13 9WH, UK Tel: + 441612761234 E-mail: auleon@aol.com

Received: 17 March 2006 Accepted in revised form: 8 June 2006 Published online: 14 July 2006

This study has been accepted for a poster presentation in the Royal College of Ophthalmologist Congress 2006 
and treatment of cataracts, achieve high-volume and high-quality surgery, provide high-quality information to patients, and audit outcomes. This resulted in the proliferation of dedicated cataract service departments, both in-house and in Diagnostic and Treatment Centres (DTC) specifically geared to meet these needs. 5,6 The increasing number of high-volume cataract centres manned by experienced surgeons has led to questions regarding the feasibility of continuing to train junior ophthalmologists in cataract surgery, in that the opportunity for them to undertake surgery may be considerably reduced. ${ }^{7-13}$ Many experienced ophthalmologists and trainees have voiced their concerns over the impact on surgical training of the introduction of new policies such as 'Action on Cataracts'. ${ }^{7-12}$ Although the benefit of such policies on current patient care are obvious, for example, by reducing waiting times and improving the quality of care overall from diagnosis to surgery, the impact on the patient of the future has not been considered. How are the trainee ophthalmologists of today to become the experienced cataract surgeons of tomorrow? The provision of training is essential to provide quality ophthalmic care in the future. However, there have been reports in the literature demonstrating a decline in the quantity of cataract surgery being performed by trainee ophthalmologists in recent years. ${ }^{9,10}$

At the Manchester Royal Eye Hospital (MREH), part of Central Manchester and Manchester Children's University Hospital's Trust, the delivery of cataract surgery has dramatically changed over the last 5 years. Previously, all cataract surgery was performed in our dedicated ophthalmic theatres at MREH. Operating lists were led by consultants usually accompanied by their team of trainees, both subspecialist surgery and cataracts could be undertaken on the same list. In 2002, as a result of the 'Action on Cataracts', a dedicated Cataract Services department was designed to provide a separate streamlined, efficient, high-volume cataract service through its own distinct cataract assessment, day case, and theatre area at the MREH. This was designed to run in parallel with the aforementioned traditional MREH service for cataract patients. The Cataract Services department was a consultant-led service. Patients would be assessed by trained optometrists as well as ophthalmologists for suitability and consented by the latter. Pre-op assessment would be performed on the same day. Patients would then return for their surgery under local anaesthesia. All of the surgery was carried out by consultant ophthalmologists or cataract fellows, although occasionally surgery was performed by senior specialist registrars eligible to apply for a consultant post. These were not training lists, so no trainees were allocated to attend. The majority of the cataract operations were still performed in the main theatre complex in the MREH on the consultants' routine theatre lists. In order to achieve government targets for waiting time, a number of waiting list initiative lists were undertaken in the MREH in addition to this. These were usually additional lists performed by consultants and fellows.

In April 2005, an NHS DTC was opened in the Withington Community Hospital, Manchester., ${ }^{5,6}$ Our in-house Cataract Services department was closed. The MREH obtained the contract to provide cataract services at this unit, which was designed to provide similar one stop high-quality service to patients as the previous 'in-house' department had done. However, it would represent an expansion on the number of patients going through the service as the number of operating lists undertaken would increase. All surgery was to be limited to adult patients suitable for local anaesthesia. Any patient requiring general anaesthesia, monitoring, in-patient stay for social or medical reasons, or complex surgery would be listed at the MREH. Each list generally consists of 7-8 cataract operations. The service is still consultant led with the majority of MREH consultants undertaking a surgical session at the DTC. As this reduced their surgical list at the MREH, this could have had a significant impact on training. Therefore, one specialist registrar is allocated to each list. Senior house officers are currently not allocated to attend the DTC.

We aimed to assess the impact of these changes in cataract treatment provision at the MREH on training by evaluating the number of operations performed by different grades of ophthalmologists over a 6-year period.

\section{Materials and methods}

Surgery at the DTC commenced on the 1 April 2005. We chose to compare the first 6 months of cataract surgery undertaken in the Central Manchester and Manchester Children's University Hospital's Trust with the same 6-month time period over the preceding 5 years. All cataract extractions performed were identified from Theatreman ${ }^{\circledR}$ computerized theatre log. Surgeries were coded to have been undertaken in one of the four types of lists:

MREH- Manchester Royal Eye Hospital standard operating list

CSL- Cataract Service List; performed in the Cataract Service Department. CSL started in 2002 and finished in March 2005

WLI- Waiting List Initiative list; performed in MREH theatre as additional list, often out of hours 
DTC- Diagnostic and Treatment Centre list from April 2005.

All surgeons were identified by their specific codes and divided into Consultants, Fellows, Specialist Registrars (SpR), or Senior House Officers (SHO). Only SpRs and SHOs were defined as trainees in this study. SpRs were subdivided in two groups for further analysis as it was considered that their opportunities may be different depending on how far on in the training programme they were:

$S p R$ Jnr - junior registrar in the first and second year of their training

SpR Snr- senior registrar in the third year and above.

Training lists were defined as those theatre sessions where trainees were assigned to attend and allowed to operate if cases were suitable. They include all operations performed at MREH or the DTC only. Neither CSL nor WLI were training lists.

Statistical analysis was performed using GraphPad Prism and Instat statistical software (GraphPad Software Inc., San Diego, CA, USA, version 4.0). In this study, $P$-values of $<0.05$ were considered as indicating statistical significance. The data were analysed using $\chi^{2}$ tests for trend.

\section{Results}

The total number of cataract operations performed in the Central Manchester and Manchester Children's University Hospital's Trust as NHS patients in the 6-month period between 1 April and 30 September, for all years from 2000 to 2005 inclusive are illustrated in Table 1. The total number of operations performed increased slightly from 2000 to 2004, with a small drop in year 2005. The number of operations performed on standard MREH lists declined significantly over the years $\left(P<0.001 \chi^{2}\right.$ test for trend), as the Cataract Services Department increased its output from 434 in year 2002 to 800 in year 2004, whereas the DTC performed 1310 cataract operations in the first 6 months of opening.

Table 1 Number of cataract extractions undertaken by location and date

\begin{tabular}{lrrrrr}
\hline & Total & MREH & CSL & WLI & DTC \\
\hline 2000 April-Sept & 2000 & 1677 & & 323 & \\
2001 April-Sept & 1696 & 1373 & & 323 & \\
2002 April-Sept & 1933 & 1263 & 434 & 236 & \\
2003 April-Sept & 2292 & 1241 & 723 & 328 & \\
2004 April-Sept & 2210 & 1152 & 800 & 258 & \\
2005 April-Sept & 2086 & 699 & & 77 & 1310 \\
\hline
\end{tabular}

The number of operations performed as Waiting List Initiatives also declined gradually.

The number of cataract operations performed on training lists declined gradually between 2000 and 2004 (Table 2). However, the number almost doubled in 2005 with the opening of the DTC as these lists were open to trainees. The number of cataract operations performed by both SpRs and SHOs demonstrated a statistically significant decline over the years $(P<0.001$ for both cases, $\chi^{2}$ test for trend), with the SHOs number dropping dramatically over the last 2 years (Figure 1). Despite the fact that the total number of operations performed by trainees has not altered greatly between 2004 and 2005 (575 in year 2004 vs 554 in year 2005), the actual percentage dropped from 50 to $28 \%$. This suggested that consultant surgeons and fellows were performing a high proportion of the operations on each list since the opening of the DTC. It is important to note that the number of training posts in the MREH has not altered much over the study period. The number of SHOs remained at six, whereas there were 16 SpRs from 2000 to 2002, increased to 17 in 2003.

Table 2 Number of cataract extractions undertaken in training lists by date and surgeons

\begin{tabular}{lcrrrr}
\hline & $\begin{array}{c}\text { Number in } \\
\text { training } \\
\text { lists }\end{array}$ & SpR & SHO & $\begin{array}{c}\text { Percentage } \\
\text { of surgery } \\
\text { performed } \\
\text { by SpR }\end{array}$ & $\begin{array}{c}\text { Percentage } \\
\text { of surgery } \\
\text { performed } \\
\text { by SHO }\end{array}$ \\
\hline 2000 April-Sept & 1677 & 709 & 152 & 42.27 & 9.1 \\
2001 April-Sept & 1373 & 528 & 223 & 38.45 & 16.2 \\
2002 April-Sept & 1263 & 482 & 165 & 38.163 & 13.1 \\
2003 April-Sept & 1241 & 535 & 203 & 43.11 & 16.4 \\
2004 April-Sept & 1152 & 456 & 121 & 39.58 & 10.5 \\
2005 April-Sept & 2009 & 485 & 69 & 24.14 & 3.4 \\
\hline
\end{tabular}

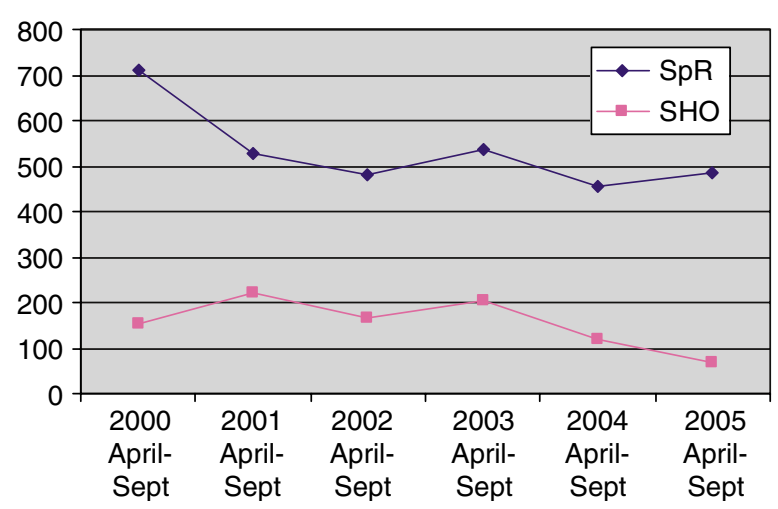

Figure 1 Line graph demonstrating the number of cataract operations performed by SpRs and SHOs over the study period. 
Table 3 Cataract operations performed by junior and senior SpRs over the study period

\begin{tabular}{lccc}
\hline & $\begin{array}{c}\text { Number } \\
\text { performed } \\
\text { by junior SpR }\end{array}$ & $\begin{array}{c}\text { Number } \\
\text { performed } \\
\text { by senior SpR }\end{array}$ & $\begin{array}{c}\text { Total number } \\
\text { performed } \\
\text { by all SpR }\end{array}$ \\
\hline 2000 April-Sept & 355 & 354 & 709 \\
2001 April-Sept & 230 & 298 & 528 \\
2002 April-Sept & 256 & 226 & 482 \\
2003 April-Sept & 176 & 359 & 535 \\
2004 April-Sept & 79 & 377 & 456 \\
2005 April-Sept & 137 & 348 & 485 \\
\hline
\end{tabular}

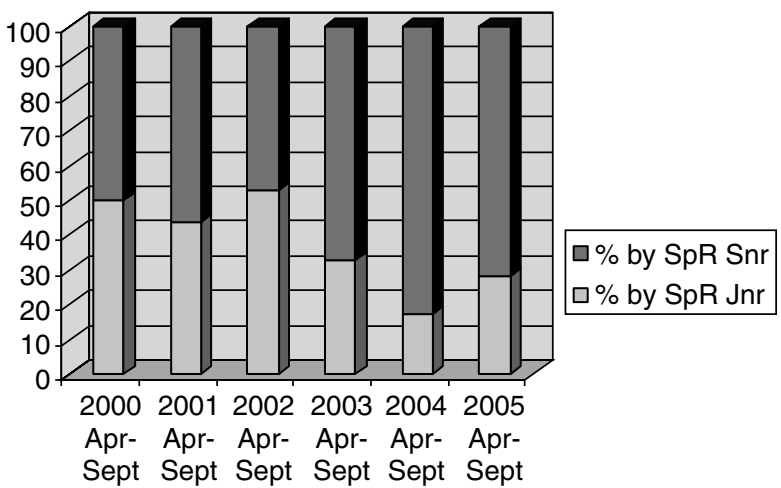

Figure 2 Bar graph demonstrating the proportions of cataract operations performed by junior SpRs and senior SpR over the study period.

When comparing the number of operations performed by junior SpRs and senior SpRs, shift in the balance can be seen towards the senior surgeons (Table 3). The proportion of operations performed by junior SpRs declined from $50 \%$ in 2000 to $28.2 \%$ in 2005 (Figure 2).

\section{Discussion}

The delivery of cataract care has changed substantially in recent years, as a result of government targets and policies. There has been concern among trainees and trainers that surgical training opportunities are diminishing and a new generation of less-skilled consultant may arise. ${ }^{8-13}$ Our study aimed to evaluate the impact of changes in the provision of cataract surgery, particularly the shift of care to a DTC, on surgical training on trainees based at the MREH. Our DTC has been opened for 6 months since 1 April 2005 and thus we have compared this 6-month period with the same period over the past 6 years.

Although the total number of NHS cataract operations performed has not increased dramatically over the study period, the number performed at MREH has gradually reduced. This has the benefit of providing theatre slots for other types of ophthalmic surgery reducing the waiting time for vitreoretinal, oculoplastic, corneal, and other subspecialties. Waiting list initiative operation numbers have also reduced, indicating that waiting time targets were being met, presumably secondary to the development of improved patient services recommended by 'Action on Cataracts'.

Our results show a significant decline in the number of operations performed by both SpRs and more particularly by SHOs over the last 6 years. This is perhaps accentuated by the increase in the number of operations assigned to Cataract Services Department lists. This downward trend confirms the general impression that training opportunities are diminishing. It appears less dramatic for the SpRs until they are subdivided into juniors and seniors when it became apparent that the junior SpRs have a greater decline in the opportunities for surgery. There have been reports that basic surgical training is lacking in ophthalmic SHOs, ${ }^{9-11}$ but our results document for the first time that higher surgical training is also affected. The opening of the DTC no doubt has benefits for current patients who can be assessed in a highly efficient and specialized environment, waiting time for surgery is short, and resources are maximized. ${ }^{5,6}$ However, as there is only a limited number of theatre sessions per week, not every trainee has the opportunity to attend on a regular basis. Training becomes a more 'stop and start' process depending on various factors like the individual firm and shift pattern. More importantly, if the contract to provide service at the DTC is awarded to an alternative provider rather than $\mathrm{MREH}$, all these training opportunities may be lost. Indeed the number of cataract operations performed by the SpRs could reduce by $50 \%$.

It is a fact that high-volume cataract surgery delivered in an efficient manner reduces waiting times for such surgery. However, this does not necessarily provide an ideal environment for training. In the DTC, there are generally 7-8 patients per theatre list. With high-volume surgery comes additional time pressure, an extra hurdle especially difficult for a junior surgeon to overcome. This is confirmed by the fact that the junior registrars got a lower proportion of surgery. In addition, trainees are also less likely to learn to deal with unexpected intraoperative complications such as posterior capsule rupture. Topical anaesthesia as opposed to local anaesthetic blocks may be preferred in a high-volume list and could pose a further challenge for trainees. The current set-up often means the first and last contact between patient and surgeon is on the day of surgery. This does not facilitate the ease with which a trainee can follow a patient through the whole process from listing to postoperative recovery. 
Gibson et al ${ }^{10}$ conducted a national survey of cataract surgery training among SHOs. They found that the number of full phakos performed by SHOs increased with the number of theatre cases per week, so long as some time was protected for teaching. This, however, is in conflict with the main agenda in a DTC (NHS or Independent Sector), which has been set up specifically to optimize service delivery. When an effort was made to generate a more 'trainee-friendly' low-volume training list, at MREH for example, uncomplicated cases were already streamlined to somewhere else rendering the rest of the cases unsuitable. This is reflected by our findings that SHOs and junior SpRs were performing fewer operations over the years, while the balance shifted towards more cases being performed by senior trainees, fellows, and consultants.

With the current European Working Time Directive and the forthcoming Modernizing Medical Careers, the emphasis of our medical training focuses more on quality rather than quantity. ${ }^{1,2,14}$ The development of fast-track cataract services and a DTC in Manchester has not made allowances for the provision of such surgical training opportunities particularly for those trainees who require a little longer to achieve competency. In an environment where there is an increasing emphasis on achieving waiting time targets and a future to be ruled by 'Payments by Results', ${ }^{15}$ one must not lose sight of the training requirements of our junior doctors. Although current practice has clearly benefited the patient of today, it could be a short-sighted view not taking into account the impact on tomorrow's patients, as we may face a new generation of less-skilled consultants emerging in the NHS unless we ensure that current trainees receive the appropriate amount of surgical training. We encourage other ophthalmology units throughout the country to conduct similar studies to ours, so that a national trend can be established. A national collaborative study would be most welcome.

\section{Acknowledgements}

We thank A Maino of the North West Ophthalmic Research Group for her advice and contribution in the statistical analysis of this study.

\section{References}

1 Department of Health. Modernizing medical careers, 2004. www.dh.gov.uk.

2 Cottrell D. New curriculum. The Royal College of Ophthalmologists. www.rcophth.ac.uk.

3 The Royal College of Ophthalmologists. Curriculum for higher surgical training in ophthalmology. www. rcophth.ac.uk.

4 NHS Executive. Action on Cataracts: Good Practice guidance. NHS Executive: London, 2000.

5 Department of Health. Growing capacity-diagnostic and treatment centres, 2003. www.dh.gov.uk.

6 Department of Health. General information about treatment centers. December 2005. www.dh.gov.uk.

7 Astbury N. Letter to Lord Warner. The Royal College of Ophthalmologists website. January 2006.

8 Fielder AR, Watson MP, Seward HC, Murray PI. Action on cataracts should influence surgical training. BMJ 2000; 321: 629.

9 Watson MP, Boulton MG, Gibson A, Murray PI, Moseley MJ, Fielder A. The state of basic surgical training in the UK: ophthalmology as a case example. J Roy Soc Med 2004; 97: 174-178.

10 Gibson A, Boulton MG, Watson MP, Moseley MJ, Murray PI, Fielder AR. The first cut is the deepest: basic surgical training in ophthalmology. Eye 2005; 19: 1264-1270.

11 Guly C, Sidebottom R, Hakin K, Bates K. Challenges of private provision in the NHS: treatment centres and their effect on surgical training. BMJ 2005; 331: 1338.

12 Gibson A, Boulton M, Watson M, Fielder A. Surgical training in ophthalmology. Lancet 2002; 360: 1702.

13 Spitz L, Kiely EM, Peirro A, Drake DP, McAndrew F. Decline in surgical training. Lancet 2002; 359: 83.

14 Department of Health. European Working Time Directive (EWTD). Guidance and good practice. www.dh.gov.uk.

15 Department of Health. Payment by results. www.dh.gov.uk. 